\title{
Recognizing and Respecting the Rights of Children with Disabilities in the Classroom
}

\author{
Cornelia Schneider ${ }^{1, *}$ \\ ${ }^{1}$ Faculty of Education, Mount Saint Vincent University, Nova Scotia B3M 2J6, Canada \\ *Correspondence: Faculty of Education, Mount Saint Vincent University, 166 Bedford \\ Highway, Halifax, Nova Scotia B3M 2J6, Canada. E-mail: Cornelia.schneider@msvu.ca
}

Received: May 10, 2016 Accepted: June 27, 2016 Published: July 11, 2016

doi:10.5296/ije.v8i3.9444 URL: http://dx.doi.org/10.5296/ije.v8i3.9444

\begin{abstract}
The UN Convention on the Rights of the Child was adopted and ratified in 1990 by the UN General Assembly, and signed by most member countries of the United Nations. However, its implementation is slow, complex, and can to-date be considered as incomplete in most countries, particularly as children's rights often seem to be in contradiction with traditional perceptions of children as dependent, immature and incompetent human beings under their parents' tutelage. Furthermore, it appears that children's rights are at risk of colliding with the rights of the family. These issues are even more strongly highlighted when it comes to children with disabilities, as those children often are perceived as vulnerable and incompetent. The UN Convention on the Rights of Persons with Disabilities of 2006 emphasizes the right to full participation based on the social model of disability, including the right to inclusive education for children with disabilities. This article addresses both conventions, the contradictions within but also with each other, which impede the rights of children with disabilities as much as traditional perceptions of childhood do. It will then demonstrate how the recognition of the rights of children with disabilities can be improved by using the frameworks of sociology of childhood (Corsaro, 2015) and the work on relationship building and solidarity by Honneth (1995). Lastly, the article will give examples of how to implement and respect the rights of children with disabilities in schools, by using the example of the Index for Inclusion.
\end{abstract}

Keywords: children, disability, children's rights, disability rights, solidarity, inclusive education 


\section{Children with Disabilities and Human Rights}

Historically, people with disabilities have been recognized as a minority group that has experienced oppression and/or exclusion in many ways; for example, through segregation, infanticide, physical and psychological abuse, or institutionalisation (see Stiker, 2000). Often, their personhood has been put into question and their right to participation has been impeded under the prejudice of incompetence and/or vulnerability, both of which presupposes an inability to speak for themselves. Similarly, children have been traditionally considered the property of their parents, or under the tutelage of adults (Howe \& Covell, 2010), and were considered as immature and thus incompetent human-beings-to-become (Corsaro, 2015). The second half of the $20^{\text {th }}$ century slowly started to change some of those perceptions: consequently, the United Nations Convention on the Rights of the Child (UN, 1990) was developed in order to give due recognition to children's rights, and then 16 years later, the United Nations Convention on the Rights of Persons with Disabilities (UN, 2006). However, it must be noted that, while there might be a perception that both conventions are a culmination in the recognition of the human rights of specific minority groups, much still needs to be done as one can observe in the country reports to the United Nations; for example, the alternative country report for Canada by the Canadian Coalition for the Rights of Children (CCRC, 2011), which shows that especially vulnerable groups of children, such as aboriginal or immigrant children, require special attention in the implementation of the convention. Similarly, the UN Convention on the Rights of Persons with Disabilities of 2006 often represents the starting point in the implementation of the rights for this group. Implementation and monitoring evidently go hand in hand in the recognition of human rights, and each country that has signed and ratified the conventions, is obligated to monitor and to report to the United Nations on the progress that has been made in regards to the requirements of the conventions. Being important milestones in the promotion of human rights, however, governments have also been frequently accused of using those UN conventions to pay lip service to human rights, but to not really implement them, as there are very few ways of sanctioning a country who is not following its obligations as outlined in the conventions.

Children with disabilities are mentioned in both conventions; however, the perspectives on disability in both conventions are different, and at times contradictory, as they follow different models of disability. Their rights are also at risk of being in contradiction with traditional perceptions of childhood and disability, as well as in competition with parental or family rights.

In this article, I will firstly address ways in which children with disabilities are included in both the Convention on the Rights of the Child (CRC) and the Convention on the Rights of Persons with Disabilities (CRPD), and why those conventions constitute progress for the rights of children with disabilities. Secondly, I will analyze why these rights are also being impeded by the contradictions in the conventions themselves and by the lack of education of the adults and adult experts involved in their creation. Lastly, the article will address what needs to be done in schools and classrooms in order to implement a rights respecting curriculum, especially when it comes to children with disabilities. 
Using a hermeneutical approach (e.g. Gadamer 1998; Chambers 2003) which is "a philosophical effort to account for understanding as an ontological-the ontological—process of man.” (Palmer 1969, 163), the article will, with the support of literature pertaining to the issue of children's rights and disability rights, analyze the central tenets of the UN Conventions on the Rights of the Child and on the Rights of Persons with Disabilities and their impact on educational systems and schools. In addition, the frameworks of Sociology of Childhood (children's agency) and Disability Studies (the medical and social models of disability) will be addressed to show how accessibility and inclusion go hand in hand with the recognition of the rights of children with disabilities in education.

\section{Children with Disabilities in the Convention on the Rights of the Child}

Generally speaking, the Convention on the Rights of the Child (CRC), which was signed in 1989 and ratified by the United Nations General Assembly in 1990, is covering three types of rights, often referred to as the 3Ps: provision, protection, and participation (see e.g. UN, 1990; Covell \& Howe, 2001). For example, the right to access adequate healthcare (article 24) falls under provision rights, protection from all forms of exploitation (article 32) is part of the protection rights, and freedom of expression (article 13) is a participation right. Depending on the context, these rights encounter moderate to significant obstacles to their implementation, depending on available resources for basic human rights such as clean water, sufficient food or access to medical care, the existence and monitoring of child protection measures, or the access to social or political participation. Each set of those rights has its own challenges, because of different cultural and socioeconomic contexts as well as traditional preconceived notions of childhood as being incomplete and immature, which do not recognize children as full bearers of rights.

The CRC also emphasizes the right to education:

Education is of special importance in the Convention. [...] Children's education rights can be divided along three tracks. First, children have the right to education. Under article 28, children have the right to free primary education and to accessible secondary and higher education. Under article 23, children with disabilities have the right to special assistance and care in education as well as in other areas. Second, children have rights in education. Under article 2, they have the right to non-discrimination. Under article 12, they have the right to participate in educational decisions that affect them. And under articles 13, 14 and 15, they have the rights to freedom of expression, freedom of thought and religion, and freedom of association and peaceful assembly, subject to reasonable limits. (Howe \& Covell, 2010, p. 93)

The CRC acknowledges more specifically the rights of children with disabilities under Article 23 paragraph 3:

Recognizing the special needs of a disabled child, assistance [...] shall be provided free of charge, whenever possible, taking into account the financial resources of the parents or others caring for the child, and shall be designed to ensure that the disabled child has 
effective access to and receives education, training, health care services, rehabilitation services, preparation for employment and recreation opportunities in a manner conducive to the child's achieving the fullest possible social integration and individual development, including his or her cultural and spiritual development. (UN, 1990)

Article 23 is calling to provide the child with disabilities with the means of accessing education and other services to respond to their special needs. The CRC addresses the rights of the child with disabilities under a protective and provisionary lens, following the medical model of disability ("special needs of a disabled child" (UN, 1990), see for example Barnes \& Mercer, 2010). The medical model of disability considers the person's disability as an issue stemming from the person's condition that needs to be treated and requires specialized care. This model does not address the issue of a maladapted and ableist environment. Furthermore, the CRC does not insist on the right to full inclusive education, but rather simply promotes the idea of access to education and services; it does not spell out where or how supports should be located or put forth ways in which these rights should be made practicable (Kayess \& French, 2008).

\section{Children with disabilities in the Convention on the Rights of Persons with Disabilities}

The Convention on the Rights of Persons with Disabilities (CRPD) was adopted by the United Nations General Assembly in 2005, as a result of a long consultation process with many international disability advocacy groups. It was deemed necessary, as people with disabilities worldwide continue to experience discrimination and oppression in various forms, based on their perceived otherness and vulnerability. The Convention's rights, similar to the rights articulated in the CRC, can be divided up into three different areas; namely, rights to protection, rights to special services, and rights to full participation. The convention does not name children as a separate group, but addresses the right to inclusive education in article 24 (UN, 2006):

[...] States Parties shall ensure that:

a) Persons with disabilities are not excluded from the general education system on the basis of disability, and that children with disabilities are not excluded from free and compulsory primary education, or from secondary education, on the basis of disability;

b) Persons with disabilities can access an inclusive, quality and free primary education and secondary education on an equal basis with others in the communities in which they live;

c) Reasonable accommodation of the individual's requirements is provided;

d) Persons with disabilities receive the support required, within the general education system, to facilitate their effective education;

e) Effective individualized support measures are provided in environments that maximize academic and social development, consistent with the goal of full inclusion. 
The CRDP, in opposition to the CRC, does not rely only on the medical model of disability, but actually draws from three different models. It contains "three disparate discourses relating to rights - namely, rights to full participation, rights to special services and rights to protection - draw off different supposedly oppositional models of disability- namely, the social, medical and protective models” (Mckenzie \& Macleod, 2012, p. 16). The social model of disability (Barnes \& Mercer, 2010) expresses that disability is caused by the way the environment and society is organized and built, rather than by a person's impairment. Thus, the social model aims at social and cultural change rather than at "fixing" the person's impairment. As Mckenzie \& Macleod (2012) highlight, those models are often seen as oppositional. If it comes to the rights of children with disabilities, one might once again encounter competing rights and obstacles to the implementation of rights, as views on vulnerability and incompetence might cause people to protect children with disabilities at the expense of infringing on their participation rights and/or infantilizing them. People with disabilities have been struggling for a long time to be recognized as full members of society, and this struggle is far from over. Many feel that the social model of disability speaks to their struggles for social change, social participation, and accessibility in society, even if this model has also been criticized at times as being too radical, focusing too strongly on the environment, and not enough on a person's condition (Shakespeare, 2013).

In opposition to the CRC, the CRDP is also calling decidedly for full inclusion when it comes to education and schooling. The place where education and schooling of children with disabilities should take place is very clearly located within the "general education system" (UN 2006, Art. 24) as one of the foundation of human equality.

\section{Commonalities, Contradictions and Challenges of both Human Rights Conventions}

As outlined above, both conventions have three types of rights (CRC: Provision, Protection and Participation; CRPD: Protection, Special provisions, Full participation) that appear to be very similar in what they want to achieve and in which types of rights they have enshrined.

However, evidently, the two conventions are not using the same frameworks when it comes to children with disabilities. While the CRC mostly relies on a medical perspective on children with disabilities, the CRDP uses different models and pushes more vehemently for participation, inclusion and accessibility for persons with disabilities. Today, the social model is widely recognized in the disability community as the tool for social change, and resonates strongly in the CRDP. While the medical model has certain merits, it has been widely criticized as a model that 'puts the blame' on the individual for the disability, and does not do enough to recognize the necessity for social change.

The contradictions between these models lie in the very core of both conventions, as the right to participation is anchored in both. Both conventions contain different types of rights that need to be implemented, and with this comes the risk of those rights being in competition with each other. For example, traditional understandings of childhood and/or disability will impede social participation, if adult-experts consider a child to be too disabled and/or too 
immature to influence the decision. The 'best interest of the child,' which is often invoked in the CRC, is too often defined by stakeholders who are not the children themselves, and who are relying on perceptions of the child stemming from a linear view of development (Corsaro, 2015). Medical and psychological notions of disability "pathologize children who do not achieve universally standardized developmental targets, seeing the disability as consequence of impairment. [There is] little awareness of the possibility that disability and a lack of ability to meet targets associated with developmental stages may have social and cultural roots." (Davis, Watson \& Cunningham-Burley, 2008, p. 222). Davis \& Watson (2000) are expressing concerns of an attitude that might "allow children's opinions to be overlooked on the grounds of 'safety' (when inclusion in decision making processes could harm the child) or 'competency' (when the child is not thought capable of understanding the process)” (p. 212). Those concerns generally apply to linear development perspectives of children (Corsaro, 2015), but are further underscored when children are considered to have a disability, as their perceived incompetence and immaturity ‘doubles up’.

As a consequence, the recognition of the rights of those children becomes highly complex, as experts and families might focus on provision and protection rather than social participation and inclusion. For example, parents and teachers might dismiss the wish of a child with disabilities to attend the same school as her peers, relying on the reasoning that a special school might provide for more support for children with a disability, and would not be as overwhelming as a general school (Schneider, 2009).

Another example could be seen in the case of Emily vs Brant Board of Education in Canada of 1997 (see Berg \& Schneider, 2012), where the final decision to withdraw Emily, a 12 year old girl with cerebral palsy from a full inclusion setting in favour of partial inclusion was made by the Supreme Court of Canada on the grounds of meeting her needs. In this particular case, the Court argued that Emily's right to non-discrimination was being met in a partial inclusive setting, as opposed to a full inclusive setting as the parents had requested for her. The court decided on this matter based on the Canadian Charter of Rights and Freedoms, but one might wonder if the ratification of the CRPD which only happened nine years later would have made a difference to this decision, as the convention gives a clear mandate to social change in favour of universally accessible spaces and participation. Another part of this decision shows that the case was argued mainly between the parents and the school board, which asks for the question if the girl herself was sufficiently consulted on her wishes.

\section{Recognizing the Child with a Disability as a social Actor}

The challenge of recognizing the rights of children with disabilities is twofold: it is necessary to overcome social perceptions of both childhood and disability, where social perceptions are often based on deficiency or narrow concepts of developmental norms. On the one hand, children with disabilities are facing the same issue as all children: they are seen as immature and incompetent, so their agency is not recognized. Moreover, the common perception is usually a linear view of development (Corsaro, 2015), which considers children as beings to become, or as incomplete adults. Similarly, persons with disabilities have been struggling to 
make their voices heard and change the perception that they are incapable of making decisions for themselves and that they are lacking the skills to participate fully in society. Again, those perceptions stem from a medicalized and a very linear view of human development. Under those circumstances, children with disabilities are perceived as 'doubly vulnerable and incompetent', thus, putting their participation rights in an even more precarious situation.

The field of Sociology of Childhood and Childhood Studies has been challenging these notions of incompetence and immaturity at the core of its paradigm. It certainly had a strong influence on the creation of the CRC, but it has also used the convention to push for a strong research agenda developing the paradigm for childhood and children (Prout \& James, 1997), which understands childhood as a social construction, worthy of study in its own right. Furthermore, this paradigm recognizes children's agency:

Children are and must be seen as active in the construction and determination of their own social lives, the lives of those around them and of the societies in which they live. Children are not just the passive subjects of social structures and processes. (Prout \& James, 1997, p. 8)

Instead of a linear view on childhood development, Corsaro develops the notion of “interpretive reproduction” (2015, p. 18). Corsaro states:

The term interpretive captures the innovative and creative aspects of children's participation in society. [...] children create and participate in their own unique peer cultures by creatively taking or appropriating information from the adult world to address their own peer concerns. The term reproduction captures the idea that children are not simply internalizing society and culture, but are actively contributing to cultural production and change. The term also implies that children are, by their very participation in society, constrained by the existing social structure and by societal reproduction. (p. 18)

The Orb Web Model (Corsaro, 2015, p. 25) captures this term graphically as well. Corsaro depicts how children are evolving in a net of relationships, social institutions and are progressing in widening fields. The growth process in this model does not occur in a linear and normative fashion, but in cycles and a growing radius, depending on the context of each child.

This paradigm and framework, under which researchers in the field of Childhood Studies are working, has demonstrated multiple times that children with disabilities are also social actors, thus they have agency and actively contribute to society. For example, children are key in providing data for research projects such as the "Life as a Disabled Child" (Shakespeare, 2005), which examined the lives of children with disabilities age 5-16 in the UK and was part of the larger ESCR Children 5-16 Research Programme that lasted 5 years and funded 22 linked research projects examining children's lives. My own studies on the quality of peer relationships in inclusive classrooms showed that children with disabilities can be active research participants who are able to express very clearly their experiences, concerns, 
strategies and desires when it comes to their own lives and futures (e.g., Schneider, 2007; 2009; 2011).

The right to freedom of expression and thought, and consequently, to participate in political processes and research, is crucial to build knowledge about children's lives, which in turn would promote and enhance the implementation of the rights of children with disabilities.

Honneth, in his work, The Struggle for Recognition: The Moral Grammar of Social Conflicts (1995), shows that recognition cannot only come from the recognition of one's rights, but that recognition can only occur if there are three different levels of recognition: love/relationships - rights - solidarity. Concretely, this means that, on one side, building relationships and being personally connected with the individuals experiencing exclusion and oppression is necessary. Secondly, on the other side, a general sense of solidarity in society needs to exist as well, so that recognition can come into power. As Habermas (1990, p. 244) puts it,

Justice concerns the equal freedoms of unique and self-determining individuals, while solidarity concerns the welfare of consociates who are intimately linked in an intersubjectively shared form of life - and thus also to the maintenance of the integrity of this form of life itself. Moral norms cannot protect one without the other: they cannot protect the equal rights and freedoms of the individual without protecting the welfare of one's fellow man and of the community to which the individuals belong.

Solidarity encompasses social cohesion, the mutual responsibility that links two or more persons (Zoll, 2001). According to Cohen \& Arato (1992, pp. 383-384),

Discursive situations within a single society, in which conflicts over norms are adjudicated, establish the possibility of such solidarity, because one can put oneself in the place of the other, grasp what his or her needs and interests are, and discover, constitute, or reaffirm commonalities and collective identity. Such processes should enrich the self-understanding of all the actors involved. On the other side, solidarity makes discourse meaningful and reaffirms the logic of reciprocal recognition at its heart. In other words, we can have solidarity with others with whom we share a collective identity without sharing or even necessarily liking their personal needs and values.

Thus, recognition of rights cannot be limited to them just being legal rights. In order to live them, relationships need to be built, and alliances/solidarity with other social groups need to be formed. In the spirit of building relationships, Nedelsky (2008, p. 141) stresses the imperative of relationships:

The first is to examine the rights dispute (e.g., competing interpretations, advocating change in traditional meaning, debating what the list of constitutional rights should be) to determine what the values at stake are. The second is to ask what kinds of relationships would foster those values. The third is to determine how competing versions of a right would structure relations differently. 
This is a very essential step in the recognition of rights, as children are experiencing their agency not as autonomous, independent human beings, but as actors in a network that connects them with their families and their peers, inside their age group, as well as between generations. As Davis \& Watson (2000) emphasize, it is not about the entirely autonomous child, but rather about "the need for co-operation between adult and child" (p. 226). Children define themselves in relationships with adults and are depending on cooperation with adults to enjoy their rights to the fullest. This is also true and indispensable especially for children with disabilities.

\section{Schools, Inclusive Education and a Rights Respecting Curriculum}

\subsection{Relationship Building and Quality of Inclusive Education}

The previous section has already hinted at pathways to respect the rights of children in general, and specifically the rights of children with disabilities. Here, I will elaborate in greater detail what this could mean concretely in a school or classroom setting, and how teachers need to be prepared for this task.

Children with disabilities have often been silenced, as adults and adult experts have often decided for them what schooling, education, therapy, etc., would be best for them. This has resulted in the segregation of many children from their peers under the pretext that their education would be served better in a different school or institution, thus infringing on the right to full inclusion as well as the right to participate in the decision making process. The growing inclusive education movement has been somewhat of a game changer, as it realizes the right of children with disabilities to learn together with everybody else. However, as I have pointed out in previous publications (e.g. Schneider, 2011; 2015), the quantity of children with disabilities included does not necessarily equal with the quality of inclusive work. This means that a generalized movement towards inclusive education in name only, without the accompanying social and societal framework of truly inclusive education, can still result in disrespecting the rights of children with disabilities.

If children with disabilities are placed in a regular classroom without re-considering the ways in which teaching and learning are occurring, and teachers and students being unable to build those indispensable relationships with the child with disabilities, then it will be difficult to establish an inclusive culture where full participation of the child with disabilities is guaranteed, or even possible. Thus, the right to inclusive education needs to go hand in hand with the right to participate in the classroom culture. We still do not know nearly enough about how children with disabilities are experiencing inclusive education, and in what ways we might need to change that. Children and youth have, at times, expressed their issues with the inclusive system, and why they would prefer to be in a specialized setting (see Pitt \& Curtin, 2004; Schneider \& Harkins, 2009), which shows that in order to be truly inclusive, the mainstream settings need to change. By listening to the children, and their families, who the system is working to include, the quality of inclusive education could be considerably enhanced (Naraian, 2013). Graham \& Slee (2008) ask the most important questions: 
Fundamentally, we must ask what assumptions might inform our personal and collective philosophies in relation to inclusive education? What do we mean when we talk of including? What happens? Whose interests are being served? And most of all, into what do we seek to include? (p. 290, italics in original text)

These questions need to also be answered by the children with disabilities themselves. This is where the field of Childhood Studies and Sociology of Childhood can help deliver the development of methods on how to access the knowledge and expertise of the children themselves, in their political right as participants in shaping their own environment. An instrument like the Index for Inclusion can become invaluable support to reach this goal.

\subsection{The Index for Inclusion as a Tool for a Rights-Respecting School Community}

Developed by Disability Studies scholars, the Index for Inclusion (Index) is:

a set of materials to support the self-review of all aspects of a school, including activities in playgrounds, staff rooms and classrooms and in the communities and environment around the school. It encourages all staff, parents/carers and children to contribute to an inclusive development plan and put it into practice (Booth \& Ainscow, 2011, p. 9).

The Index is now in its third revised edition and has been translated into more than 40 languages. The Index is not prescriptive, as it does not set norms such as what an inclusive school should look like, but it asks questions that help a school community to reflect on their current reality, and guide them towards things in which they could start change or improvement. The authors of the Index stress that everyone who is present in the school should be involved in this process, from janitorial staff to administration, teachers, parents and students. Processes like the one offered by the Index for Inclusion can deliver on the promise to respect the rights of everyone, as they are taking into account everybody's voice, and have the potential to establish change where needed. The Index for Inclusion contains three dimensions: A: Creating Inclusive Cultures; B: Producing Inclusive Policies; C: Evolving Inclusive Practices. These dimensions enclose 70 indicators that can be examined by the school community. Each indicator has a set of questions that help to evaluate what the school community is already doing to fulfill this goal as well as indicate what is lacking. The Index contains a range of indicators that are directly related to the implementation of rights. For example:

\section{A1.7 The school is a model of democratic citizenship}

A2.2 The school encourages respect for all human rights

A2.7 The school counters all forms of discrimination

B1.1 The school has a participatory development process

C1.13 Children learn about ethics, power and government

If one looks more closely at indicators A2.2, one can find questions that assess directly the school's involvement with human rights, for example: 
b) Does the school encourage a belief that everyone has rights and they have them equally? c) Is respect for rights encouraged in the way that adults and children treat each other? [...] d) Is it recognised that a person's rights can only be limited when exercising them directly infringes the rights of others? (Booth \& Ainscow, 2011, p. 88).

By offering these sets of indicators and questions, the Index assists in the evaluation of an inclusive practice that is anchored both in children's rights and disability rights. It does not offer readymade solutions, but gives each school community the opportunity to evaluate their own cultures, policies and practices, and develop a plan for change from there. Children (students) are part of this process, and have input on how to implement an inclusive and rights-respecting environment.

The implementation of rights-respecting schools (Covell \& Howe, 2008) needs several dimensions. As outlined above, there is the aspect of direct participation of children (with disabilities) into the process of implementing rights and in creating an inclusive school environment. Furthermore, there is the dimension of education of all stakeholders about children's rights and disability rights. This goes from the teachers and school staff to the parents as well as to the children themselves. Oftentimes, the UN conventions are not well known, or are met with a lot of skepticism. In Canada, people often do not make the connection between the different UN Human Rights Conventions and their own Charter of Rights and Freedoms of 1982 (Canadian Charter of Rights and Freedoms, 1982). We often recognize rights as far as we are able to imagine their implementation, but stop right where it seems to become too challenging or requires systemic change. When it comes to the rights of children with disabilities, generally, we are often too quick to express our doubts that those rights could possibly be implemented, from the right to political participation, to inclusive schooling, as well as other issues.

\section{Concluding Thoughts}

This article has demonstrated a close connection between children's rights and disability rights, but has also revealed some contradictions when it comes to implementing and upholding both sets of rights. Many aspects of these contradictions speak to the traditional ways that children and persons with disabilities are viewed in society. However, as this article also shows, the path towards resolving these contradictions may be found in the new, progressive ways that encourage participation, inclusion and accessibility.

The field of Sociology of Childhood and Childhood Studies, as well as the field of Disability Studies, continue to contribute a lot to changing views on children with disabilities. There is growing awareness that not only do they have the right to provision, protection and participation, but they also have the ability to contribute to their own environment, make choices, and participate in the socio-political processes surrounding them. Childhood Studies also has shown that we need to rethink our ways of interacting with children with disabilities (Davis, Watson \& Cunningham-Burley, 2008). Even if children with disabilities are not able to participate verbally, or experience other obstacles to communication, there are other ways 
of engaging with them, and finding out what their aspirations and desires are. Ethnographic research has shown that if we as adults leave our personal assumptions behind and take the position as a reflective researcher, then we are able to uncover a plenitude of ways to interact, as well as ways to build meaningful relationships with those children, which in turn leads us to support their participation and inclusion (see e.g. Corsaro 2015; Eder 1995, Davis, Watson \& Cunningham-Burley 2008, Cavet \& Sloper 2004). The same should be expected from the teacher as a reflective practitioner who is working with children in classroom settings. Once they have been able to build a relationship, then the educator can get a clearer picture of the ways of implementing the child's rights in a classroom setting. Children's agency has been submerged and/or undermined by assumptions of incompetence, immaturity and vulnerability; it is thus even more important now to follow the path of the conventions to unearth those aspects of childhood and disability that we have not been able to see. If we as adults are able to develop our relationships and our solidarity with children with disabilities, it will help us to recognize them.

\section{References}

Barnes, C., \& Mercer, G. (2010). Exploring disability: A sociological Introduction (2nd Ed.). Cambridge, UK: Polity Press.

Berg, D. H., \& Schneider, C. (2012). Equality dichotomies in inclusive education: Comparing Canada and France. ALTER - European Journal of Disability Research / Revue Européenne De Recherche Sur Le Handicap, 6(2), 124-134. http://dx.doi.org/10.1016/j.alter.2012.02.011

Booth, T. \& Ainscow, M. (2011). Index for inclusion. Developing learning and participation in school (3rd ed.). Bristol, UK: Centre for Studies on Inclusive Education.

Canadian charter of rights and freedoms, Part I of the Constitution Act, 1982, being Schedule B to the Canada Act 1982 (UK), 1982, c 11. Retrieved from http://laws-lois.justice.gc.ca/eng/const/page-15.html

Canadian Coalition for the Rights of Children (CCRC, 2011). Right in principle, right in practice: Implementation of the convention on the rights of the child in Canada. Retrieved from http://rightsofchildren.ca/wp-content/uploads/CCRC-Report-to-UN-on-CRC.pdf

Cavet, J., \& Sloper, P. (2004). Participation of disabled children in individual decisions about their lives and in public decisions about service development. Children \& Society, 18(4), 278-290. http://dx.doi.org/10.1002/CHI.803

Chambers, C. (2003). 1002/CHI.803 bled children in individual decisions about their lives and in public decisions about service development. International handbook of curriculum research (pp. 221-252). Mahwah, NJ: Lawrence Erlbaum Associates.

Cohen, J., \& Arato, A. (1992). Civil society and political theory. Cambridge, MA: MIT Press. 
Corsaro, W. A. (2015). The sociology of childhood (4th ed., Sociology for a new century series). Thousand Oaks, CA: SAGE.

Covell, K., \& Howe, R. B. (2001). The challenge of children's rights for Canada. Waterloo, ON: Wilfrid Laurier University Press.

Covell, K., \& Howe, R. B. (2008). Rights, respect and responsibility: Final report on the county of Hampshire rights education initiative, September 2008. Retrieved from http://www.cbu.ca/sites/cbu.ca/files/pdfs/crc-pub-rights-respect-responsibility-2008.pdf

Davis, J. \& Watson, N. (2000). Disabled children's rights in every day life: Problematising notions of competency and promoting self-empowerment. The International Journal of Children’s Rights, 8(3), 211-228. http://dx.doi.org/10.1163/15718180020494622

Davis, J., Watson, N. \& Cunningham-Burley, S. (2008). Disabled children, ethnography and unspoken understanding: The collaborative construction of diverse identities. In Christensen, P. \& James, A. (Eds.), Research with children: Perspectives and practices (pp. 220-238). Hoboken, NY: Taylor \& Francis.

Eder, D. (1995). School talk gender and adolescent culture. New Brunswick - New Jersey: Rutgers University Press.

Gadamer, H.-G. (1998). Truth and method. (2nd revised ed. J. Weinsheimer \& D. G. Marshall, Trans.). New York, NY: Continuum.

Graham, L. J., \& Slee, R. (2008). An Illusory Interiority: Interrogating the discourse/s of inclusion. Educational Philosophy and Theory, 40(2), 277-293. http://dx.doi.org/10.1111/j.1469-5812.2007.00331.x

Habermas, J. (1990). Justice and solidarity: on the discussion concerning stage 6. In T. Wren (Ed.), The Moral Domain. Essays in the Ongoing Discussion between Philosophy and the Social Sciences (4th ed.), pp. 224-251). Cambridge, MA: MIT Press.

Honneth, A. (1995). The struggle for recognition: The moral grammar of social conflicts. Cambridge, UK: Polity Press.

Howe, R. B., \& Covell, K. (2010). Miseducating children about their rights. Education, $\begin{array}{llll}\text { Citizenship and Social 5ustice, } & \text { 5(2), }\end{array}$ http://dx.doi.org/10.1177/1746197910370724

Kayess, R., \& French, P. (2008). Out of darkness into light? Introducing the Convention on the Rights of Persons with Disabilities. Human Rights Law Review, 8(1), 1-34. http://dx.doi.org/10.1093/hrlr/ngm044

Mckenzie, J. A., \& Macleod, C. I. (2012). Rights discourses in relation to education of people with intellectual disability: Towards an ethics of care that enables participation. Disability \& Society, 27(1), 15-29. http://dx.doi.org/10.1080/09687599.2012.631795

Muir, K., \& Goldblatt, B. (2011). Complementing or conflicting human rights conventions? Realising an inclusive approach to families with a young person with a disability and 
challenging behaviour. Disability \& Society, 26(5), 629-642. http://dx.doi.org/10.1080/09687599.2011.589195

Naraian, S. (2013). Dis/ability, Agency, and Context: A differential consciousness for doing inclusive education. Curriculum Inquiry, 43(3), 360-387. http://dx.doi.org/10.1111/curi.12014.

Nedelsky, J. (2008). Reconceiving rights and constitutionalism. Journal of Human Rights, 7(2), 139-173. http://dx.doi.org/10.1080/14754830802071950

Pitt, V., \& Curtin, M. (2004). Integration versus segregation: The experience of a group of disabled students moving from mainstream school into special needs further education. $\begin{array}{llll}\text { Disability } \quad \text { and } & \text { Society } & \text { 387-400. }\end{array}$ http://dx.doi.org/10.1080/09687590410001689485

Prout, A. \& James, A. (1997). A new paradigm for the sociology of childhood? Provenance, promise and problems. In A. James \& A. Prout (Eds.), Constructing and reconstructing childhood (pp. 7-33). London, UK: Routledge Falmer.

Schneider, C. (2007). Être intégré, être en marge, être reconnu ? L’enfant en situation de handicap et son statut social dans une classe ordinaire, Education et Sociétés, 20, 149-166. http://dx.doi.org/10.3917/es.020.0149

Schneider, C. (2009). Equal is not enough - Current Issues in Inclusive Education in the Eyes of Children. International Journal of Education, 1(1), E1. http://dx.doi.org/10.5296/ije.v1i1.101

Schneider, C. (2011). Une étude comparative de l'éducation inclusive des enfants avec besoins particuliers en France et en Allemange: Recherches dans onze salles de classe $=$ A comparative study of the inclusion of children with special needs in mainstream schools in France and Germany: case studies of eleven classrooms. Lewiston, N.Y: Edwin Mellen Press.

Schneider, C. (2015). Social participation of children and youth with disabilities in Canada, France and Germany. International Journal of Inclusive Education, 19(10), 1068-1079, http://dx.doi.org/10.1080/13603116.2015.1037867

Schneider, C., \& Harkins, M. J. (2009). Transatlantic Conversations about Inclusive Education: France and Nova Scotia. Research in Comparative and International Education, 4(3), 277-288. http://dx.doi.org/10.2304/rcie.2009.4.3.276

Shakespeare, T. (2005). Life as a disabled child: A qualitative study of young people's experiences and perspectives. ESRC Full Research Report, L129251047. Swindon: ESRC. Retrieved from http://www.esrc.ac.uk/my-esrc/grants/L129251047/read

Shakespeare, T. (2013). Disability rights and wrongs revisited (2nd ed.). London, UK: Routledge.

Stiker, H. J. (2000). A History of Disability. Ann Arbor, MI: University of Michigan Press. 


\section{Macrothink}

International Journal of Education

ISSN 1948-5476 2016, Vol. 8, No. 3

United Nations (UN, 1990). United Nations convention on the rights of the child. Retrieved from http://www.ohchr.org/en/professionalinterest/pages/crc.aspx

United Nations (UN, 2006). United Nations convention on the rights of persons with disabilities.

Retrieved

from

http://www.un.org/disabilities/convention/conventionfull.shtml

Zoll, R. (2001). Le défi de la solidarité organique. Avons-nous besoin de nouvelles institutions pour préserver la cohésion sociale? Revue du Mauss, 18(2), 105-118. http://dx.doi.org/10.3917/rdm.018.0105

\section{Copyright Disclaimer}

Copyright for this article is retained by the author(s), with first publication rights granted to the journal.

This is an open-access article distributed under the terms and conditions of the Creative Commons Attribution license (http://creativecommons.org/licenses/by/3.0/). 